УДК 547.8:547.665:615.28:579.61

ФОТОСЕНСИБИЛИЗАТОРЫ ХЛОРИНОВОГО РЯДА

ДЛЯ АНТИМИКРОБНОЙ ФОТОДИНАМИЧЕСКОЙ ТЕРАПИИ

${ }_{1,2,3}$ Кустов А.В., ${ }^{2}$ Гарасько Е.В., ${ }^{4}$ Белых Д.В., ${ }^{4}$ Худяева И.С., ${ }^{4}$ Старцева О.М., 1,3 Макаров В.В., ${ }^{2}$ Стрельников А.И., ${ }^{3}$ Березин Д.Б.

${ }^{1}$ ФГБУН «Институт химии растворов им. Г.А. Крестова»

Российской академии наук, Иваново;

${ }^{2}$ ФББОУ ВО «Ивановская государственная медииинская академия», Иваново;

${ }^{3}$ ФББОУ ВО «Ивановский государственный химико-технологический университет»,

НИИ Макрогетероциклов, Иваново;

${ }^{4}$ ФГБУН «Институт химии» Коми научного иентра УрО Российской академии наук,

Cызктылвкар, e-mail: kustov@isuct.ru

Проведено исследование антимикробной активности шести фотосенсибилизаторов (ФС) хлоринового ряда в отношении фирмикутных бактерий Staphylococcus aureus, грациликутных бактерий Escherichia coli и грибов Candida albicans. Показано, что использование ФС, адсорбированных на твердых поверхностях, в случае плотных питательных сред в целом малоэффективно. Катионные ФС, в зависимости от величины заряда и положения заряженной группы в молекуле, при испытании в жидких питательных средах и невысоких концентрациях ФС (0,00005 моль/кг) обнаруживают высокую токсичность в отношении Staphylococcus aureus и Candida albicans, однако, практически не проявляют антимикробной активности в отношении грам-отрицательных микроорганизмов. Напротив, гидрофобное производное хлорина е 6 с фрагментом 2,3-дигидроксиметил-1,4-хиноксалина обладает достаточно высокой световой токсичностью в отношении всех трех видов микроорганизмов, что позволяет на данном этапе считать его перспективным для проведения антибактериальной фотодинамической терапии (ФДТ).

Ключевые слова: хлорины, фотосенсибилизаторы, антимикробная активность, фотодинамическое действие, Escherichia coli, Staphylococcus aureus, Candida albicans

\title{
CHLORIN PHOTOSENSITISERS \\ FOR ANTIMICROBIAL PHOTODYNAMIC THERAPY
}

1,2,3 Kustov A.V., ${ }^{2}$ Garasko E.V., ${ }^{4}$ Belykh D.V., ${ }^{4}$ Khudyaeva I.S., ${ }^{4}$ Startseva O.M., ${ }^{1,3}$ Makarov V.V., ${ }^{2}$ Strelnikov A.I., ${ }^{3}$ Berezin D.B.

${ }^{1}$ G.A. Krestov Institute of Solution Chemistry of the Russian Academy of Sciences, Ivanovo;

${ }^{2}$ Ivanovo State Medical Academy, Ivanovo;

${ }^{3}$ Ivanovo State University of Chemistry and Technology, Research Institute of Macroheterocyclic Compounds, Ivanovo;

${ }^{4}$ Chemistry Institute of Komi Republic Scientific Centre of Ural branch of Russian Academy of Sciences, Syktyvkar, e-mail: kustov@isuct.ru

\begin{abstract}
The investigation of antimicrobial activity of six chlorin photosensitizers (PS) in relation to of firmicutes Staphylococcus aureus, gracilicutes Escherichia coli and fungi Candida albicans was performed. The using of PS which are adsorbed on solid surfaces are ineffective in the case of dense nutrient medium. According to the charge and the position of charged groups in the molecule, the cationic PS in liquid media at low PS concentrations $(0.00005 \mathrm{~mol} / \mathrm{kg})$ were tested. Their high toxicity against Staphylococcus aureus and Candida albicans and the absense of antimicrobial activity in relation to gram-negative microorganisms were shown. In contrast, the hydrophobic chlorin $\mathrm{e}_{6}$ derivative with a fragment of 2,3-dihydroxymethyl-1,4-quinoxaline has a sufficiently high light toxicity against all three types of microorganisms, which allows to consider it as a promising antimicrobial drug for photodynamic therapy (PDT).
\end{abstract}

Keywords: chlorines, photosensitizers, antimicrobial activity, photodynamic effect, Escherichia coli, Staphylococcus aureus, Candida albicans

Возрастающая полирезистентность патогенных микроорганизмов и особенно их госпитальных штаммов стала одной из наиболее грозных проблем здравоохранения многих стран мира [2, 7, 13]. Если в 1970-е гг. впервые были замечены микроорганизмы, устойчивые к целым группам антибактериальных препаратов, то в конце 1990-х гг. уже появились штаммы, приобретшие устойчивость ко всем известным тогда антибиотикам. Казалось бы, с открытием антибиотиков такие тяжелые инфекционные процессы, как сепсис, перитонит, гангрена стали совершенно управляемыми, однако уже сегодня, вследствие 
предопределенной генетически высокой приспосабливаемости бактерий к условиям среды, они опять уносят жизни миллионов людей.

Генетический аппарат бактерий достаточно прост и включает всего лишь одну хромосому, содержащую порядка 3000 генов, и плазмиды - содержащие не более пары сотен генов, которые, однако, очень мобильны. Многие из этих участков ДНК, являясь транспозонами, легко перемещаются из плазмиды в плазмиду или непосредственно в хромосому, что обеспечивает их быстрое распространение внутри популяций, видов и даже между различными видами бактерий. Эти процессы в ходе борьбы за существование, наряду со спонтанными мутациями, являются основными причинами появления приобретенной устойчивости микроорганизмов к еще вчера высокоэффективным препаратам $[6,13]$. Изменения проницаемости клеточной стенки, модификация мишени, выработка ферментов являются основными общепризнанными причинами постепенно развивающейся устойчивости микроорганизмов к антибактериальным препаратам [6, 13]. В частности, хорошо известно [3], что применение большинства лекарственных средств класса бета-лактамов в терапии современных внутрибольничных инфекций сопряжено с высоким риском неудачи, что требует назначения дорогостоящей и не всегда возможной целевой эмпирической комбинированной антибиотикотерапии. В этой связи, очевидно, что поиск новых эффективных методов борьбы с бактериальными инфекциями, и в особенности с их нозомикальными штаммами, обладающими перекрестной резистентностью, является одним из несомненных приоритетов отечественного здравоохранения.

Антибактериальная фотодинамическая терапия (ФДТ) представляет собой принципиально отличную от антибиотикотерапии стратегию лечения множества заболеваний, основанную на селективном накоплении и удерживании в атипичных или поврежденных клетках человека, а также непосредственно в клетках микроорганизмов окрашенных веществ - фотосенсибилизаторов (ФС). Эти вещества при воздействии видимого света определенной длины волны и соответствующей мощности гене- рируют активные формы кислорода, что позволяет эффективно инактивировать атипичные клетки и микроорганизмы путем запуска каскада фотохимических реакций $[8,9,11,12,15]$. К настоящему времени в клинической практике используется ряд ФС для диагностики и лечения онкологических заболеваний, гнойно-воспалительных заболеваний ЛОР-органов, обработки ран и т.д. $[8,9,11,12,15]$. В отличие от антибиотиков противомикробное действие ФДТ не снижается со временем, а у патогенов не развивается устойчивости к ней $[11,15]$. Бактерицидный эффект при этом лимитируется зоной лазерного облучения сенсибилизированных тканей, что позволяет избежать при проведении ФДТ генерализации побочных эффектов, наблюдаемых при применении антибиотиков и антисептиков. Заживление происходит по типу естественных репаративных процессов, поэтому метод является наиболее органосохраняющим, а также легко переносимым, что позволяет повторять лечение при необходимости многократно.

Вместе с тем использование существующих фотосенсибилизаторов для антибактериальной ФДТ имеет свои недостатки. В меру нашего понимания данной проблемы важнейшими из них являются высокая стоимость лечения, длительная остаточная фототоксичность для ряда препаратов, таких как «Фотогем» и «Фотосенс», недостаточная степень чистоты ряда ФС, часто представляющих собой смесь родственных соединений $[8,9]$. Нами был синтезирован, очищен и идентифицирован ряд соединений хлоринового типа (соед. 1-6) с целью разработки препаратов для антибактериальной ФДТ. С целью моделирования внутриклеточного транспорта была изучена их способность к генерации синглетного кислорода, распределение между псевдолипидной и водной фазами $[4,5,16]$.

В настоящей работе представлены результаты лабораторного исследования антимикробной активности полученных препаратов в отношении дрожжеподобных микроскопических грибов (Candida albicans CCM 8261 ATCC 90028), грамположительных (Staphylococcus aureus 6538-P ATCC = 209-P FDA), грамотрицательных (Escherichia coli M-17) бактериальных штаммов. 


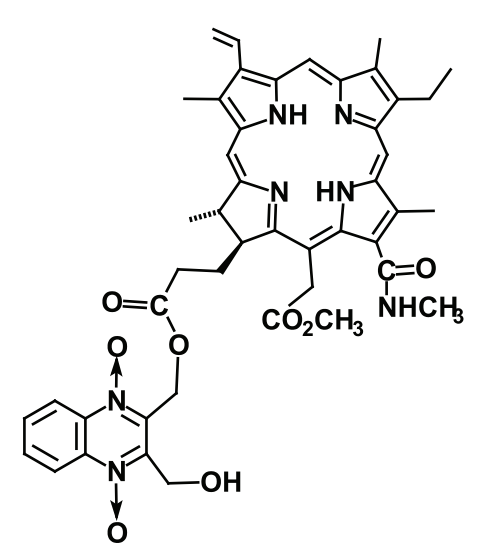

1

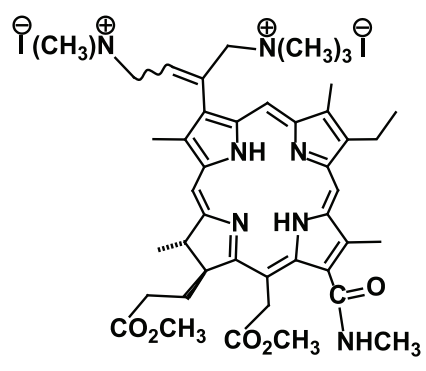

4
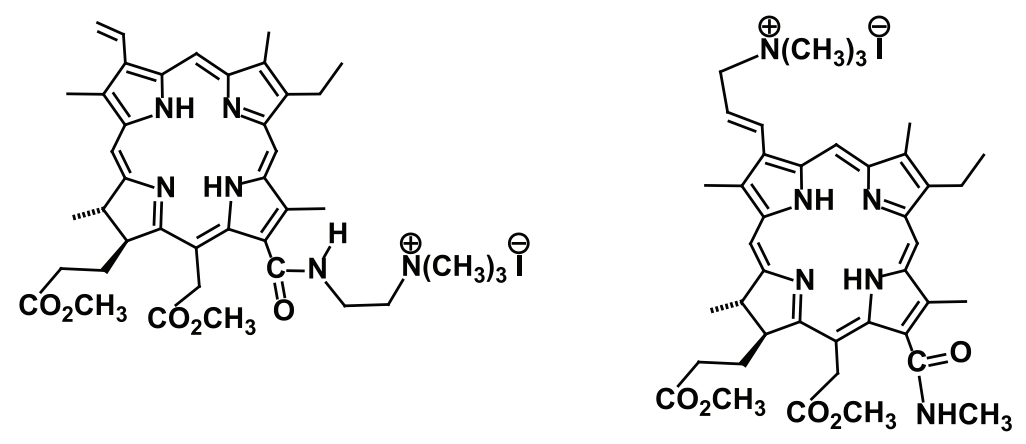

2

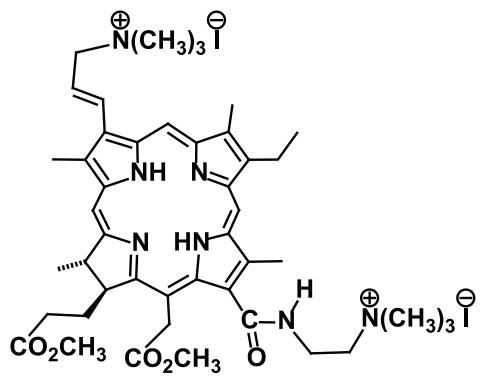

5
3

6

\section{Материалы и методы исследования}

Синтез, очистка и идентификация препаратов

Изученные фотосенсибилизаторы (соед. 1-6): 1 - 17(3)-(2,3-дигидроксиметил-1,4-хиноксалин)$13(1)-\mathrm{N}$-метиламид хлорина $e_{6}, 2-13(1)-\left(\mathrm{N}^{\prime} \mathrm{N}^{\prime \prime} \mathrm{N}^{\prime \prime}-\right.$ триметиламиноэтил)амид хлорина $e_{6}$ йодид; 3 - 3(2)-(N'N"N"'-триметиламинометил)-13(1)-Nметиламид хлорина е6 йодид; 4 - 3(1),3(2)-бис( $\mathrm{N}^{\prime} \mathrm{N}{ }^{\prime \prime} \mathrm{N}^{\prime \prime}$-триметиламинометил)-13(1)-N-метиламид хлорина $e_{6}$ дийодид; 5 - 3(2)-( $\mathrm{N}^{\prime} \mathrm{N}^{\prime \prime} \mathrm{N}^{\prime \prime \prime}-$ триметиламинометил), 13(1)-(N'N"N"'-триметиламиноэтил) амид хлорина $e_{6}$ дийодид и $6-3(1), 3(2)$-бис( $\mathrm{N}^{\prime} \mathrm{N}^{\prime \prime} \mathrm{N}^{\prime \prime}$ - триметиламинометил), $13(1)-\left(\mathrm{N}^{\prime} \mathrm{N}^{\prime \prime} \mathrm{N}^{\prime \prime}-\right.$ триметиламиноэтил)амид хлорина $e_{6}$ трийодид были получены путем химической модификации хлорофилла, а точнее, его производного метилфеофорбида a, выделенного экстракцией из сине-зеленой водоросли Spirulina Platensis $[1,10,14]$. Очистку препаратов проводили путем колоночной хроматографии, а также перекристаллизацией. Спектральную идентификацию полученных соединений проводили методами масс-спектрометрии, ядерного магнитного резонанса и электронной спектроскопии. Подробная методика синтеза и идентификации соединений будет описана позднее в специализированной статье.

Растворы ФС готовились следующим образом. Препараты 2-6 готовились путем непосредственного растворения заданного количества вещества в воде для достижения концентрации $10^{-4}$ моль/кг. Нерастворимый в воде ФС 1 предварительно был растворен в небольшом количестве ацетона, содержащем расчетное количество ТВИН 80. Затем ацетон был выпарен под вакуумом при температуре $50^{\circ} \mathrm{C}$ и постоянном перемешивании. Далее к полученной вязкой жидкости под действием ультразвука (40 кГц; 70 Вт) постепенно добавлялось расчетное количество $10 \%$ водного раствора этанола до образования мицеллярного раствора ФС с содержанием ПАВ 1 мас.\%. Проведенный анализ показал, что полученный раствор оставался стабильным в течение 2-3 недель.

Методика подготовки посевной дозы тесткультур

Суточные культуры тест-штаммов на скошенном мясопептонном агаре смывали физиологическим раствором и доводили до концентрации 500 млн микробных клеток в 1 мл (5 единиц по оптическому стандарту мутности). Посевную дозу 1000 клеток в 1 мл готовили из исходной стандартной взвеси многократным разведением.

Посев тест-культур на плотные питательные среды

На плотные питательные среды проводили посев описанных тест-культур. В чашки Петри с плотной питательной средой вносили 1 мл (1000 клеток) тесткультуры бактерий или грибов. Посев Staphylococcus aureus проводили в чашки Петри с желточно-солевым агаром (ЖСА), Escherichia coli - в чашки Петри co средой Эндо, Candida albicans - в чашки Петри со средой Сабуро. На подсушенные среды с тесткультурой накладывали исследуемые образцы, представляющие собой обработанные водным раствором соответствующего ФС кусочки фильтровальной бумаги, размером 7,5×7,5 мм. Через полчаса проводили сеанс ФДТ. Далее чашки Петри инкубировали 24 часа в термостате при $37^{\circ} \mathrm{C}$. О результатах испытаний судили по степени угнетения зоны роста тест-культуры вокруг исследуемых образцов.

Посев тест-культур в жидкую питательную среду

В этой серии экспериментов в каждую лунку четырех стандартных луночных планшетов вносили 0,5 мл мясопептонного бульона с тест-культурой микроорганизмов (посевная доза 1000 клеток) и 0,5 мл 
раствора фотосенсибилизатора. Через полчаса инкубации проводили сеанс ФДТ. Далее планшеты выдерживали 24 ч при температуре $37^{\circ} \mathrm{C}$. Для подтверждения наличия бактерицидных свойств у исследуемых образцов проводился высев из всех лунок на чашки Петри с плотной питательной средой для подсчета колониеобразующих единиц (КОЕ).

\section{Моделирование ФДT in vitro}

Моделирование антибактериальной ФДТ проводили в затемненном помещении при комнатной температуре путем облучения чашек Петри или планшетов с тест-культурами с помощью специального светодиодного источника видимого света («БМЦ», Минск) с регулируемой мощностью излучения и водяным охлаждением. Максимальная мощность излучения светодиодного планшета 0,2 Вт/см², площадь засвечиваемой поверхности $100 \mathrm{~cm}^{2}$, диапазон длин волн падающего света $660 \pm 15$ нм. Мощность излучения, расстояние до образца и время воздействия подбирались таким образом, чтобы обеспечить равномерное засвечивание исследуемых бактериальных

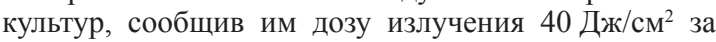
время проведения обычной физиотерапевтической процедуры в клинике $\sim 15$ мин.

\section{Результаты исследования и их обсуждение}

\section{Антибактериальная ФДТ на плотных питательных средах}

Результаты проведенных исследований показали, что при нанесении красителей на фильтровальную бумагу и помещении ее на плотную питательную среду с микроорганизмами, не все исследуемые образцы после проведенного облучения подавляют рост тест-культур: Staphylococcus aureus, Escherichia coli и грибов Candida albicans. В первой серии экспериментов при нанесении одной капли раствора ФС концентрацией 0,0001 моль/кг на фильтровальную бумагу, относительно высокую активность в отношении золотистого стафилококка продемонстрировали образцы 2, 3, 4 (рисунок), показавшие зоны задержки роста на среде ЖСА 15, 14 и 14 мм соответственно. В отношении Escherichia coli и грибов Candida albicans какой-либо антибактериальной активности установить не удалось.

Во второй серии экспериментов исследуемые образцы наносили на фильтровальную бумагу путем погружения ее в раствор ФС и далее раскладывали в чашки Петри со средами ЖСА, ЭНДО, Сабуро, содержащими тест-культуры. И в этом случае была подтверждена незначительная активность $\Phi С$ в отношении микроорганизмов. Лишь образцы 3 и 4 показали зону задержки роста (по 12 мм) в отношении золотистого стафилококка. Был сделан вывод, что при нанесении красителя на бумагу он достаточно сильно связывается с целлюлозой, что наряду с использованием в экспериментах плотной питательной среды ослабляет диффузию ФС и накопление его в достаточном количестве в микробных клетках. Отсюда следует, что использование, например, любых текстильных материалов, пропитанных растворами препаратов, при нанесении на раневую поверхность для проведения ФДТ может оказаться неэффективным из-за недостаточного увлажнения раны и малого времени инкубации. Для плотных сред это время должно быть, по-видимому, значительно больше 30 минут.

\section{Результаты испытаний образиов в жидкой питательной среде}

В эксперименте с жидкими питательными средами перед проведением ФДТ смешивали в равных количествах раствор ФС с концентрацией 0,0001 моль/кг и мясопептонного бульона, содержащего исследуемую тест-культуру. Далее раствор выдерживали при комнатной температуре в течение получаса и проводили сеанс ФДТ. Оценивали как темновую, так и световую токсичность исследуемых препаратов с рабочей концентрацией 0,00005 моль/кг.

Как видно из рисунка, до облучения образцы 1 и 2 дали сплошной рост культуры стафилококка и, таким образом, не обладали темновой цитотоксичностью (собственным антибактериальным действием), остальные образцы роста не показали. После облучения образец № 1 - дал рост 43 КОЕ, образец № 2 - не дал роста, что демонстрировало их высокую антимикробную активность после облучения сенсибилизированной культуры $(95,7$ и $100 \%$ эффективность - соответственно), остальные образцы не дали роста.

При исследовании темновой цитотоксичности в отношении грибов Candida albicans образцы 1, 2, 4 не дали роста, то есть фактически обладали темновой цитотоксичностью. Наоборот, образцы, обладавшие темновой цитотоксичностью в отношении стафилококка $3,5,6$ дали рост - 30, 12 и 8 КОЕ соответственно. После сообщения препаратам дозы 40 Дж/см² рост дал только образец 3 (6 КОЕ), что демонстрировало прекрасный антимикробный эффект (80\% у образца № 3 и $100 \%$ у образцов № 5 и 6 , которые не дали роста).

Изучение антибактериальной активности ФС в отношении грамотрицательного патогена - кишечной палочки привело к весьма неожиданным результатам. Как видно, до облучения все образцы дали 


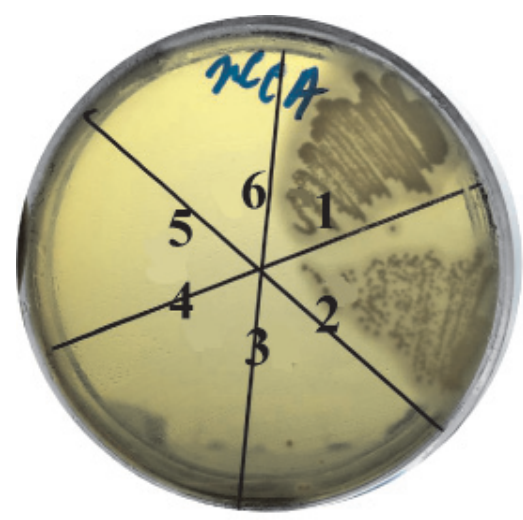

a

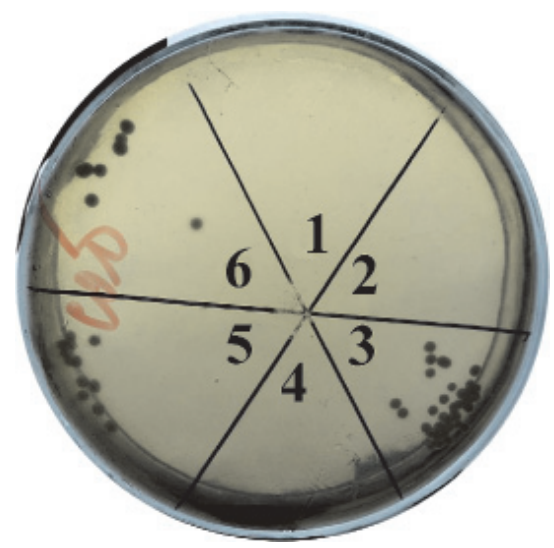

б

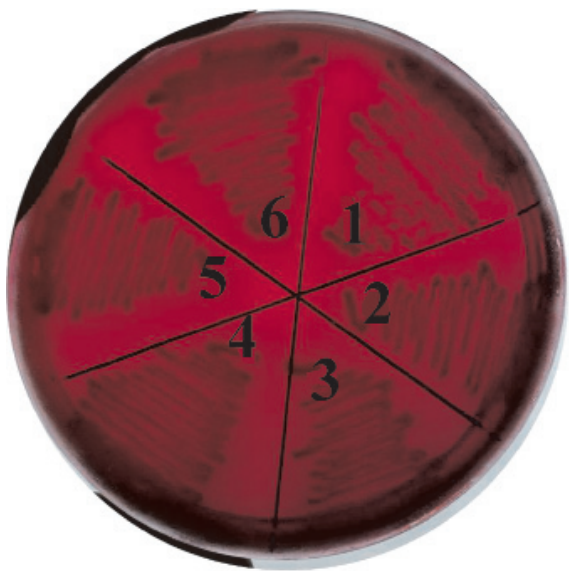

B

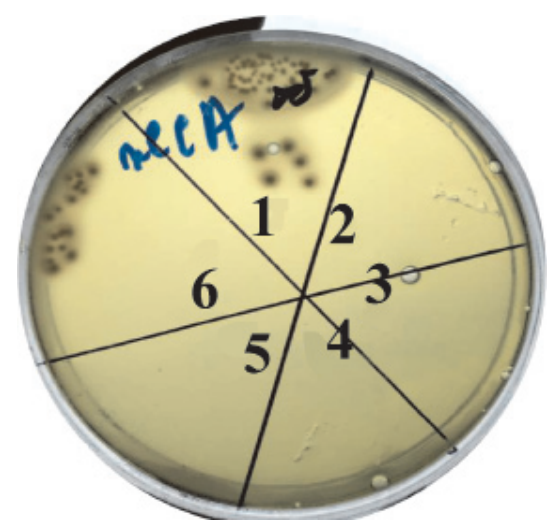

$\mathrm{a}^{\prime}$

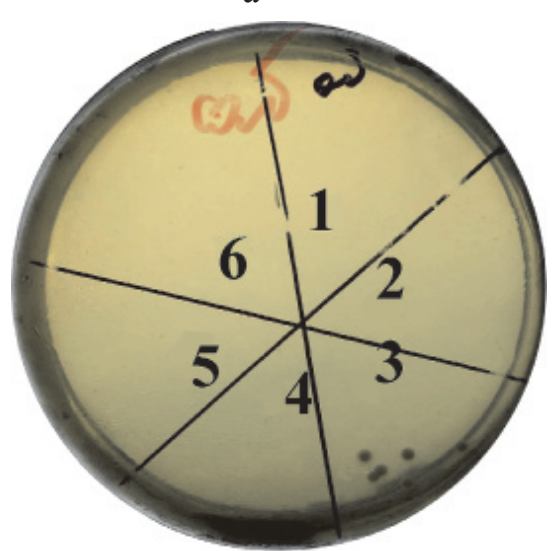

$\sigma^{\prime}$

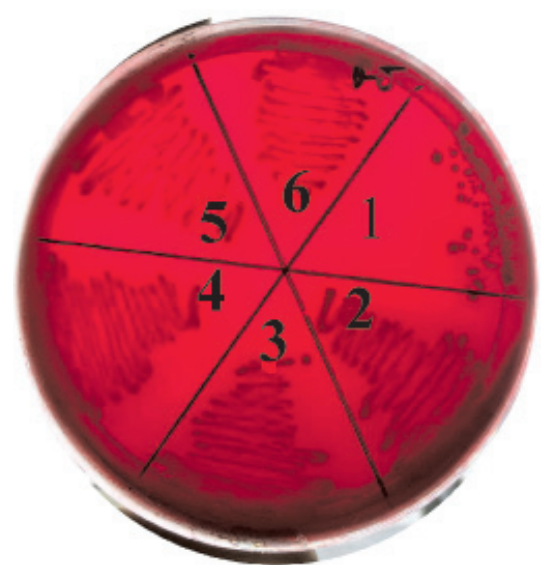

$\mathrm{B}^{\prime}$

Pост колоний Staphylococcus aureus ( $\left(\right.$, $\left.a^{\prime}\right)$, Candida Albicans $\left(6, \sigma^{\prime}\right)$ u Escherichia coli (6, в') на питательных средах, содержащзих ФС (нумеращия на рисунке соответствует номерам

соединений) до (a, б, в ) и после однократного облучения $\left(a^{\prime}, \sigma^{\prime}, в^{\prime}\right)$ видимым светом с дозой 40 Дж/см². Нумераиия секторов соответствует номерам соединений 1-6

сплошной рост культуры E. coli. После облучения образец 1 продемонстрировал хорошее антимикробное действие, дав рост 30 КОЕ (эффективность $97 \%$ ). В остальных случаях был зафиксирован сплошной рост. Очевидно, что наблюдаемая картина связана исключительно с уникальным строением внешней оболочки грамотрицательных бактерий, имеющих внешнюю липополи- сахаридную мембрану. Как видно, лишь один самый гидрофобный препарат (1) оказался в состоянии преодолеть липополисахаридный слой и проявить выраженную антибактериальную активность. Остальные положительно заряженные и значительно более гидрофильные ФС, которые в принципе могли бы проникнуть в клетку через пориновые каналы, во время проведения 
эксперимента находились, по-видимому, на внешней поверхности мембраны, что и предопределило отсутствие антибактериального действия.

\section{Выводы}

Проведенное нами исследование антибактериальной активности пяти ФС хлоринового ряда в отношении фирмикутных бактерий Staphylococcus aureus, грациликутных бактерий Escherichia coli и грибов Candida albicans показало, что использование ФС, адсорбированных на твердых поверхностях, в случае плотных питательных сред в целом малоэффективно. По результатам испытаний установлено, что лишь моно- и дизаряженные ФС (соед. 2 и 5) демонстрируют достаточно высокую активность в отношении золотистого стафилококка. В отношении остальных микроорганизмов активности практически не обнаруживается.

При использовании жидких питательных сред показано, что катионные ФС соед. 2-6) в зависимости от величины заряда и положения заряженной группы в молекуле ФС обнаруживают как темновую, так и световую токсичность в отношении Staphylococcus aureus и Candida albicans при очень незначительных концентрациях порядка 0,00005 моль/кг. В ряде случаев после облучения удается достичь $100 \%$ гибели всех микроорганизмов. Однако в случае кишечной палочки заряженные ФС оказались неэффективными, хотя в работах $[14,15]$ отмечается, что именно катионные ФС должны проявлять антимикробную активность в отношении грамотрицательных микроорганизмов, что и было зафиксировано, в частности, для синегнойной палочки [15]. По-видимому, в нашем случае необходимо использовать более концентрированные растворы ФС и значительно увеличить время инкубации, дав возможность препаратам в достаточном количестве проникнуть внутрь микробной клетки. Увеличение дозы светового излучения также должно повысить эффективность ФДТ.

Среди исследованных соединений лишь гидрофобное диоксидиновое производное хлорина е 6 (соед. 1) обнаружило достаточно эффективное действие в отношении всех трех видов микроорганизмов при малой темновой токсичности, что позволяет на данном этапе считать его достаточно перспективным для проведения антибактериальной ФДТ.
Работа выполнена при поддержке Российского научного фонда-проект № 15-13-00096.

\section{Список литературы}

1. Белых Д.В., Синтез полифункциональных хлоринов на основе метилфеофорбида а и его аналогов. - Сыктывкар: Изд. НИИ химии Коми НЦ УрО РАН, 2012. - 164 с.

2. Березняков И.Г., Страшный В.В. Антибактериальные средства: стратегия клинического применения. - Харьков: Константа, 1997. - С. 1-200.

3. Иванов Д.В. Рациональная антимикробная фармакотерапия современных внутрибольничных инфекций: дис. ... д-ра мед. наук. - М., 2010. - 257 с.

4. Кручин С.О., Кустов А.В., Романенко Ю.В., Желтова Е.Н., Березин М.Б., Каримов Д.Р., Венедиктов Е.А., Макаров В.В., Белых Д.В., Березин Д.Б., Синтез и генерация синглетного кислорода сенсибилизаторами для фотодинамической терапии онкологических заболеваний на основе производных хлорина е6 // Химический анализ и медицина: тезисы I Всеросс. конф. - М., 2015. - С. 90.

5. Кустов А.В., Антонова О.А., Смирнова Н.Л., Кручин С.О., Березин Д.Б., Белых Д.В., Сольватация фотосенсибилизаторов на основе хлорофилла в двухфазной системе вода/1-октанол. // Тезисы Международн. конф. по термич. анализу и калориметрии в России. - СПб., 2016. - С. 86-89.

6. Сидоренко С.В. Резистентность микроорганизмов и антибактериальная терапия // Рус. мед. журн. - 1998. - № 6 (11). - С. 717-725.

7. Страчунский Л.С. Состояние антибиотикорезистентности в России // Клин. фармакол. и тер. - 2000. - № 9 (2). C. 6-9.

8. Трухачева Т.В., Шляхтин С.В., Исаков Г.А., Истомин Ю.П. Фотолон - новое средство для фотодинамической терапии. - Минск, РУП «Белмедпрепараты», 2009. - 64 с.

9. Agostinis P, Berg K, Cengel K, Foster, T, Girotti A et al Photodynamic Therapy of Cancer: an Update // CA Cancer J Clin. - 2011. - № 61. - P. 250-281.

10. Berezin D.B., Kustov A.V., Venediktov E.A., Makarov V.V., Kruchin S.O., Belykh D.V. Photosensitizers for Antibacterial PDT: Synthesis, Singlet Oxygen Generation, Hydrophilicity Control and Toxicity Assays. Abstracts of International Conference on Porphyrins and Phthalocyanines ICPP-9. - Nankin', 2016. - P. 26.

11. Biel M.A. Photodynamic Therapy of Bacterial and Fungal Biofilm Infections // In Photodynamic Therapy Methods and Protocols. Gomer Ch. G. (Ed). - P. 175-194.

12. Brandis AS, Salomon Y, Schetz A. Chlorophyll Sensitizers in Photodynamic Therapy. In Chlorophylls and Bacteriochlorophylls: Biochemistry, Biophysics, Functions and Application (Grimm B, Porra RJ, Rüdiger W, Scheer H, eds). - Springer, Berlin, Germany, 2006. - P. 461-483.

13. Dowson C. Influence of horizontal gene transfer (mosaic genes) on antibiotic resistance in Streptococcus pneumoniae and Neisseria meningitidis // Antibiotics Chemotherapy. 1998. - Vol. 2, № 2. - P. 13.

14. Gushchina O.I., Synthesis of cationic derivatives of chlorin e6 / O.I. Gushchina, (E.A. Larkina, A.F. Mironov) // Macroheterocycles. - 2014. - Vol. 7. - № 4. - P. 414-416.

15. Huang L., Dai T., Hamblin M.L. Antimicrobial Photodynamic Inactivation and Photodynamic Therapy for Infections // In Photodynamic Therapy Methods and Protocols. Gomer Ch. G. (Ed). - P. 155-174.

16. Kustov A.V., Belykh D.V., Startseva O.M., Kruchin S.O., Venediktov E.A., Berezin D.B. New photosensitizers developed on a methylpheophorbide a platform for photodynamic therapy: Synthesis, singlet oxygen generation and modeling of passive membrane transport // Pharmaceutica Analytica Acta. - 2016. - Vol. 7. - № 5. - P. 480-684. DOI: 10.4172/21532435.1000480 . 